\title{
POLICE DISCRETION AND DIVERSION OF INCIDENTS OF INTRA-FAMILY VIOLENCE
}

\author{
RaYmond Parnas*
}

\section{INTRODUCTION}

In recent years, there has been a marked increase in discussion of the diversion of appropriate categories of alleged antisocial behavior from the criminal process. The primary impetus for the growing concern is a very practical one-the "demand" for criminal justice "services" exceeds the supply. Police, jails, prosecutors, defen'ders, courts, correctional institutions, and correctional personnel are and continue to be overburdened. Each time the supply is increased, the "demand" rises to the challenge; and balancing the supply and demand, at least by traditional means, no longer appears either economically or pragmatically feasible. Even assuming that such a balance were possible and desirable, neither the public nor the government seems able to allocate tax dollars in sufficient quantities to seriously approach such a resolution. Accordingly, one solution now being explored is how to reduce the "demand" for these "services." There is a second basis for the growing interest in diversion. Although it may be viewed superficially as only idealistic, it is actually also quite pragmatic. Many categories of offenses not only consume a significant amount of the time of one or more criminal agencies, but also involve situations in which the criminal process is not a particularly appropriate or effective means for dealing with the problem-at least no better than some other existing or potential means. These types of offenses are prime targets for diversion.

Inherent difficulties for law enforcement personnel are presented by the so-called victimless crimes such as prostitution, gambling, and homosexuality. They require comparatively large expenditures of time on police surveillance or related pursuits to gather legally admissible evidence, and full prosecution of these crimes necessitates protracted hearings and appeals on issues such as entrapment and suppression of evidence. Drug cases not only possess similar subject-matter difficulties, but multiply the problems by their numerical frequency. In addition to the issue of time, the appropriateness of using the criminal process to deal with such offenses is rendered questionable by their relatively victimless nature. Accordingly, these victimless crimes provide prime material for the exercise of selective enforcement and other informal

- Acting Professor of Law, University of California, Davis.

This article represents a portion of a report made by the writer for the American Bar Foundation. The complete report including prosecutor, court, and community-based, as well as police, diversionary methods with respect to intra-family (and neighbor) violence is soon to be published by the American Bar Foundation as just one chapter in an entire book describing methods for the diversion, or noncriminal disposition, of a broad range of offenses from the criminal process. That much larger American Bar Foundation project, of which this article is a small part, was funded by a Law Enforcement Assistance Administration grant. 
diversionary procedures such as arrest and release without prosecution. Currently, there are trends in many states toward legalization of some of these activities-as in the case of private sexual conduct between consenting adults in Illinois-or legalization and regulation-as in the case of some forms of gambling in several jurisdictions and prostitution in Nevada. Similarly, there is growing discussion of the possibility of legalization and regulation of marijuana possession and use.

Public drunkenness not involving the operation of a motor vehicle is a victimless crime which, unlike the others, does not possess the inherent difficulties in prosecution, but which is a significant resource drain due to its numerical frequency. It, too, raises questions about the appropriateness of the criminal sanction. Traffic violations, due to their constant occurrence and marginal criminality, probably surpass even public drunkenness as a long-standing object for discussions about diversion. A third major irritant for agencies in the criminal process is the intra-family assault. These three offense categories, drunks, traffic, and domestics, generally are acknowledged as those producing the most frequent incidents in the criminal process. ${ }^{1}$ Thus,

\footnotetext{
${ }^{1}$ As to the frequency of domestic disputes, the following examples clearly show their prevalence in this country and throughout the criminal process:

"The everyday police response to the minor family conflict probably exceeds the total number of murders, aggravated batteries, and all other serious crimes. For example, the Chicago Police Department publishes a Patrol Division Operations Report, not available to the public, one subcategory of which is 'disturbances.' 'Disturbances' includes minor family conflict (domestic disturbances), teen disturbances, party noise, and the like. The report for the Irth Police Period, Oct. 13, 1966 to Nov. 9, 1966, shows a total of 134,869 calls for police service in the city of Chicago. Of this total of 134,869 calls, $17 \%$ are classified as 'Criminal Incidents.' This category includes crimes as serious as murder and as minor as bicycle theft. The remaining $83 \%$ includes, 12,544 traffic accident calls, 2,009 vehicle recovery calls, and 96,826 'Misc. Non-criminal' incidents. Hence, 'Misc. Non-criminal' includes about $80 \%$ of all calls for police service during the period. One third of Misc. Non-criminal' incident calls are 'disturbances.' 'Thus the noncriminal category of all kinds of reported disturbances exceeds all reported criminal incidents by almost 40\%." Parnas, The Police Response to the Domestic Disturbance, 1967 WIs. L. REv. 914, n. 2.

A six-month study between January and June 1970 showed that Oakland, California police responded to more than 16,000 family disturbance calls with an expenditure in man hours exceeding 8,000 . In San Francisco at least 4,000-6,000 cases involving intra-family violence were processed by the Family Relations Bureau of the District Attorney's Office in fiscal year I969-70. 1969-70 ANN. REP. SAN Francisco District ATroRney 36. In the City of Los Angeles, a substantial number of the estimated I500 cases handled at the main office by the seven full-time attorneys in informal monthly hearings involved intra-family violence. This figure does not include the numerous cases handled by the three branch offices. Letter to author from Robert O. Young, Chief Complaint Deputy, Los Angeles City Attorney, Criminal Division, Jan. 4, 197I. In Washington, D.C. the U.S. Attorney's Court of General Session's Office handled $14,000-16,000$ citizen complainant walk-ins per year, morc than half of which were estimated to have been domestic disturbances. See H. Subin, Criminal Justice in a Metropolitan Court 7, 56 (1966).

The District Attorney's Misdemeanor Complaint Bureau in Detroit handles 400-600 warrant requests per month, most of which are domestic complaints. In the typical month of September, 1970, in Philadelphia the District. Attorney's Community Rights Unit handled 686 in-person citizens' requests for warrants (other than fraud), and it is estimated that about $70 \%(480)$ of these were family or ncighbor assaults. As many as $50 \%$ of the cases on the crowded daily docket of Chicago's Court of Domestic Relations involve intra-family assaults. Thus, admittedly minimal, but nonetheless case-by-case, prosecutive attention by the States Attorney is necessitated. Many of these same cases also add to the case loads of the Court's adjunct Social Service and Mental Health agencies as well as other public and private agencies. Parnas, Judicial Response to Intra-Family Violence, 54 Mins. L. REv. 585, 589-94 (1970).

An increasing number of jurisdictions are adding courts to handle nothing but family violence matters. In 1945, it was found that Manhattan's inferior criminal courts issued 10,000 summons yearly for cases
} 
without more, it is reasonable to consider the possibilities of diversion for each.

The focus of this report is on the least considered category of frequently occurring offenses, incidents of intra-family violence. By "least considered," I do not mean to imply that diversion of such matters does not occur. Actually, the handling of family disturbances presents a major example of the exercise of discretion by police, prosecutors, and judges in diverting such cases from the criminal process. However, these practices only recently have become apparent to those outside of the criminal process. In most statistical compilations, intra-family violence incidents are lumped indiscriminately into the more general categories of assault, battery, disorderly conduct, and disturbing the peace. Only in the more serious crimes of homicide and aggravated battery is any attempt made to identify the victim-offender relationship. Until very recently little empirical or analytical work had been done specifically on the family disturbance. ${ }^{2}$

\section{I}

\section{Basic Aspects of the Intra-Family Violence Dilemma}

\section{A. Nature of the Dispute}

The competing elements within domestic disputes make uncertain the role of the criminal process. A basic tenent of criminal law is to condemn the intentional commission of an act of violence by a legally responsible actor upon another human being. But in domestic disputes, the conflict is between persons with a consanguine,

involving family disputes. This resulted in the formation of Home Term Court and ultimately the Family Offenses Term of the New York Family Court. In fiscal year I966, about I5,000 cases arising in New York City involving intra-family violence were seen by the City Wide Family Offenses Term. Id. at 623 n. 102, 63I.

${ }^{2}$ An important general source of initial illumination was the $1956-57$ ABF Field Survey first reflected in the work of Wayne LaFave on arrest in 1965 . The subsequent work in this field has been almost entirely by two authors, Dr. Morton Bard of City College of New York and this reporter. Dr. Bard's publications (some jointly with Dr. Bernard Berkowitz) include: Family Disturbance As A Police Function (presented at the $2 \mathrm{~d}$ National Symposium on Law Enforcement Science and Technology conducted by the Law Enforcement Science and Technology Center, I.I.T. Research Institute, Chicago, Illinois, April 18, I968, to be published in the Proceedings of the Symposium) (mimeographed); The Community as Laboratory: Exploring Psychoanalytic Concepts 3 (presented at the Fourth Annual Conference of the Adelphi University Institute of Advanced Psychological Studies, Psychoanalytic Contributions to Community Psychology, to be published in the Proceedings) (mimeographed); Training Police as Specialists in Family Crisis Intervention: A Community Psychology Action Program, 3 Comarunity Mental Health J. 3I7 (1967); A Community Psychology Consultation Program in Police Family Crisis Intervention: Preliminary Impressions, I5 THE IN'L J. OF Soc. PsychratRx 209 (I969); The Role of Law Enforcement in the Helping System, to be published in Comm. Health J.; Alternatives to Traditional Law Enforcement, in Karten, Cook \& Lacey, Psychology and the Problems of Soctety 128 (I970); Extending Psychology's Impact through Existing Community Institutions, 24 AM. Psychologist 6ro (1969); Family Intervention Police Teams as a Community Mental Health Resource, 60 J. CrIM. \& P.S. 247 (I969); Iatronic Violence, submitted at the invitation of the National Commission on the Causes and Prevention of Violence, October 4, I968. This reporter's pertinent publications are Judicial Response to Intra-Family Violence, 54 MiNN. L.R. 585 (I970); The Response of Some Relevant Community Resources to Intra-Family Violence, 44 IND. L.J. 159 (I969); The Police Response to the Domestic Disturbance, 1967 WIs. L.R. 914. 
legal, or intimate connection which places them in a close and continuing emotional relationship. Absent serious threats or injury or repeated minor inicidents, it is arguable that the closer the relationship, the less anti-social is the violent behavior. This does not suggest that society has no interest in resolving the domestic problem. Rather, it points out that the problem is distinguishable from violence directed at a stranger or a casual acquaintance because it fits less clearly within accepted notions of criminal behavior. In fact, preservation of the family relationship context of the dispute may be deemed a very important social goal. Thus, even if the problem is regarded criminal in nature, invocation of criminal processes may damage the interdependent relationship of the offender and victim as well as cause distress for children or other family members. Physical and emotional problems may ensue not only at the time the process commences, but after it is completed. ${ }^{3}$

Admittedly, violent acts ought not to occur in domestic relationships. Yet the opportunity for such conflict between those in continuing contact is great, especially when the contact results from an emotional interdependence. Threats, assaults, and batteries are not unusual in marital conflicts, sibling disputes, and traumas in the numerous other intimate relationships. Although not rare, do such incidents nonetheless reflect a need for outside assistance? Few parents never have administered a spanking; yet the great majority of parent-child relationships survive such interaction. In the heat of adult, family battle, threats, thrown objects, slaps, kicks, and sometimes beatings may be exchanged. Perhaps the participants and the relationship will be scarred forever; but there is a theory that conflict, even if violent, may be a prerequisite to productive growth. If the problem does require outside assistance, it is questionable whether the agencies of the criminal process can provide effective measures for dealing with the complexities of family discord.

\section{B. Police Attitudes Toward Intra-Family Violence}

Regardless of the underlying nature of the problem there is a practical necessity for the police officer to respond to urgent calls for help such as "my husband is drunk and beating me up," or "he has a gun and is threatening to kill me." Once called, the officer has an opportunity-if not an obligation due to his crime prevention role-to reduce the possibility of recurrence of the violence.

Almost all police officers dislike intervening in family incidents. Most feel that handling family squabbles is not really police work. The officer's own domestic relations may account for the belief that domestic disputes are personal matters which

\footnotetext{
${ }^{3}$ Due to the proximity of the parties involved, family disturbances and neighbor disputes are analytically related both in cause and contact which continues after outside intervention in the dispute has occurred. However, in neighbor disputes the contact quotient is marginal and the more crucial elements of physical and emotional interdependence are usually totally lacking. Therefore, although some of the responses mentioned in this paper are also explicitiy applicable to neighbor disputes, caution must be exercised in applying the discussion of family violence responses too rigidly to neighbor disputes. Although actively sought, no specific tactics for handling neighbor violence other than those briefly mentioned in this paper were obtained. Accordingly, some attention to this phenomenon is warranted.
} 
should be solved without outside interference. If he perceives a need for outside assistance in' a given situation, he may interpret it as a need for a social worker rather than a policeman. The physical risks involved in domestic disputes are extreme. The danger quotient is high for both the disputing parties-a very large percentage of aggravated batteries and homicides are a result of intra-family violence -and to the officer-more officers have been killed or injured responding to these kinds of incidents daring the last ten years than in responding to any other traditional police call for service. ${ }^{4}$ Undoubtedly, this risk is an important, though usually unexpressed, factor in the distaste that police have for calls involving domestic disputes. For example, a wife who has requested police assistance may, upon seeing her husband restrained by an officer, turn and attack the officer. Despite the violent acts of her husband which precipitated the call, her emotional ties and habituated loyalty may elicit such a reaction.

The general pattern of police treatment of domestic disputes evidences recognition of the competing elements involved in family violence. Because violence and danger are present, the dispute is included in police jurisdiction. Yet, the usual failure of the officer to arrest the transgressor reflects, at least in part, an understanding that such situations are socially distinguishable from criminal activity in general.

Police respond but they generally do not arrest. Rather, police favor a temporary adjustment of the dispute. Other agencies of the criminal process often make a similar response. District attorneys listen to complaints but generally do not charge. If an arrest is made and charges are filed, the prosecutor or judge often receives a request from the victim, who has since reconciled with the offender, that the charges be dismissed. Compliance is generally summary. Finally, if a hearing does occur and conviction results, judges hesitate to incarcerate or even fine such: defendants. They fear that the results of the sanction-loss of employment, reduction of the family's already tight budget by imposition of a fine, relegation of the

\footnotetext{
"For further information related to danger in family disputes" the reader should see the annual FBI crime reports. A change of uncertain significance may be occurring with respect to homicide statistics. The 1969 Chicago Police Annual Report reflects a reduction in murders between family members, intimates, and neighbors from 1968 to 1969 . In 1968, 503 murders were motivated by a personal dispute, 65 by robbing, burglary or other motivations for a total of 647 murders. Also, of these 647 murders, III involved legal or common law marriage partners; 44, other familial members; I38, friends; 172, other acquaintances, including business; and 179 in which no relationship was established. In 1969 murders increased to 715 , but those arising out of personal disputes decreased to 50r, whereas miscellaneously motivated murders increased to 102. Murders within the context of marriage and familial relationships declined respectively to $8_{4}$ and 30 . Those among friends and acquaintances increased to 145 and 197 respectively. However, murders where no relationship was established increased greatly to 259 .

In Washington, D.C., the figures for $1966-\mathrm{Ig} 69$ show a significant increase in homicides committed by non-acquaintances and a decrease in homicides by acquaintances.
}

\begin{tabular}{lcccc}
\multicolumn{5}{c}{ Victim-Offender Relationships in D.C. Homicides } \\
Knew & Did Not Know & Unknown & Total \\
1966 & 113 & 31 & 6 & 550 \\
1968 & 124 & 48 & 18 & 190 \\
1969 & 73 & 110 & 26 & 209 \\
& 79 & I88 & 26 & 293
\end{tabular}


family to welfare, removal of the children's father figure, or exacerbation of already existing tension-may have more severe consequences for the family unit than did the crime. Thus, police, prosecutors, and judges frequently depend on brief lectures, warnings, threats, or non-existent peace bonds in an attempt to deter the commission of similar acts of violence by the defendant.

Since domestic problems are frequently removed from the criminal process by discretionary screening, it is important to consider the comparative effects of the existing diversionary methods on the re-occurrence of similar acts of violence, the succession to more major acts of aggression, and the potential breakdown of the family unit. In examining the manner in which intra-family violence is currently handled, the possible alternative approaches through non-criminal agencies-both traditional and experimental-must also be weighed. As a basis for this evaluation, the author surveyed the available literature, corresponded with involved individuals, and made field visits to innovative jurisdictions. The data collected as a result of this effort constitutes the most comprehensive accumulation of information on the handling of intra-family violence ever compiled. ${ }^{5}$

However, this report can only be classed as a preliminary evaluation of the data. Current knowledge and experience in handling such domestic crimes are not yet far enough advanced to permit formulation of a definitive scheme to the exclusion of other models. In other words, imagination, innovation, experimentation, and, most of all, implementation of a broad spectrum of ideas, some of which are suggested here, is needed.

II

\section{Traditional Diversionary Procedures}

\section{A. The Police}

Since domestic disputes involve a potential for serious injury, the quality of the police response is extremely important. Because of the frequency with which such service calls are received the element of community relations adds to the need for an effective response. These factors are also present in the parties' relationships with the other agencies of the criminal process, but the immediacy of police involvement in a family crisis makes their role crucial. The police treatment of these incidents is based on acquired experience; from department to department it generally varies only in detail. However, the beginnings of some innovation are present in a number of jurisdictions.

\section{Communications Screening}

In most "criminal" domestic disputes, the police department is the first governmental agency contacted. The initial contact usually is made by a phone call for

\footnotetext{
${ }^{5}$ Detailed reports on each facet of this study are available at the American Bar Foundation, Chicago, Illinois.
} 
service from the wife-victim, a frightened family member, or a disturbed neighbor; and the police dispatcher is generally the first state agent to communicate with the complainant. $\mathrm{He}$ is, in a very literal sense, the receptionist for the patrolmen. Like the office receptionist, he exercises extraordinary power over access to his department's services and is in a position to influence, by the questions asked and the information imparted, the immediacy and effectiveness of the services rendered. The dispatcher's significance applies to all of his contacts, not just domestic disputes; but this importance, perhaps even more than the office receptionist's, ${ }^{6}$ has been virtually ignored. ${ }^{7}$

Diversion, here better described as screening, often occurs at this early stage. The practice in Chicago is typical and illustrates the role played by the dispatcher. The usual practice in that city is to dispatch a patrol car when one is requested by the caller. However, at times, the dispatcher may recognize the voice of a chronic complainant or define a legitimate complaint as nonetheless not properly a police matter or determine that the call does not demand immediate police presence. In such cases, the dispatcher may attempt to resolve the matter over the phone by advice or referral. But if the caller continues to request police presence, a car will be sent. There are several reasons for this ultimate policy:

( 1 ) good public relations; (2) the possibility that the complaint is in fact a police matter; (3) the possibility that an unattended civil matter will become a criminal case requiring attention; (4) the prevention of repeat calls and prolonged conversations; and (5) reinforcement of 'Operation Crime-Stop' [a greatly publicized program of the Chicago Department urging citizens to report all suspicious incidents]. ${ }^{8}$

However, the results of a study of the Syracuse, New York, Police Department revealed that:

When the complainant reports a nuisance or a dispute he has only one chance in two of getting more than advice-albeit philosophical advice. ... It is possible that some of the calls about violence are later stages of these unanswered dispute calls. For example, to one complaint, "My boyfriend is mad at me and is going to beat me up," the answer was, "Call us again when he does."9

The Syracuse Police Chief described this example as "poor police practice."10 In Chicago:

Practically speaking, most dispatcher screening of calls is more a matter of advice given by the dispatcher under the persuasive influence of his police authority, which is accepted by the caller in lieu of actual police presence, rather than a denial of a citizen's demand for police service. Naturally this kind of screening depends upon the initiative, ability, and personality of individual dispatchers.

\footnotetext{
${ }^{\circ}$ See Blau, The Dynamics of Bureaucracy (1969).

${ }^{7}$ Cf. Parnas, The Police Response to the Domestic Disturbance, 1967 WIs. L. REv. 914, 922; Cumming, Cumming \& Edell, Policeman as Philosopher, Guide, and Friend, x2 Soc. Proв. 276, 281 (1965).

${ }^{8}$ Parnas, supra note 7 , at 923.

- Cumming, Cumming \& Edell, supra note 7, at 28I.

${ }^{10}$ Id. at n. 6.
} 
A common practice is to inquire whether the offender in a domestic disturbance is still on the scene. If he is not, then the dispatcher may simply advise the victim where and how to secure a warrant, and then suggest that she call the police again if the offender returns (or that she should "lock the door" or "go stay with mother"). This may often satisfy the victim's need to complain to the authorities about the offender's misconduct and it does not necessitate sending a police officer. This procedure seems to be consistent with the general policy and patrol practice of adjustment without arrest. However, if the dispatcher learns that the victim has been seriously injured (i.e., has suffered an injury requiring medical attention) or that the offender has threatened imminent return to do serious harm, then a police officer will usually be sent even though the offender is no longer present. But questions about the extent of injuries [the presence of a weapon] or the imminence of the offender's return do not appear to be asked as a matter of course.

Only a few dispatchers indicated that if they had the time they might attempt to get more details than usual about the cause of the disturbance and perhaps attempt to mediate the dispute over the phone by asking to talk to the offender. Most, however, indicated that they did not have the time, the callers wanted a car sent, or that telephone mediating was just not their job. ${ }^{11}$

Accounts of communication screening of family trouble calls in Washington, D.C., are conflicting, but all indicate that considerable screening is undertaken. At the policy level, it was reported that if an assault were in progress or imminent, a car would be sent; otherwise, the caller would be advised to lock up and to call back if the offender returned and would be told where to seek a warrant. At the operational level, the assault-in-progress criterion was reported with no mention whatsoever of the imminence of an assault as an additional criterion. From non-police sources, it was learned that although current responses were increasing, in recent years the police did not respond at all if the dispatcher knew it was a family dispute--even if the offender was said to have a gun. This practice is said to have caused a legal aid attorney to advise his clients simply to state their name and address and that someone was killing them (without indicating any relationship) when calling for police assistance in a domestic squabble.

Departmental General Orders $2 I_{45}(\mathrm{Ig} 68$ ) and 2285 which initiated the screening policy in Detroit, provide guidelines for screening specific kinds of incidents including assaults of all grades, family trouble, and neighbor trouble. Such detailed written policies are rare. The most important elements of the declared policy are as follows:

a. The goal of screening is "to insure that vital police service will be available when needed."

b. The guidelines are to be used to determine whether a scout car is needed.

c. "Before denying or granting a request for police service, the guides outlined should be closely considered as well as the complainant's ability to make an in-person report without great inconvenience." [emphasis added]

\footnotetext{
11 Parnas, supra note 7 , at 922-24.
} 
d. Rather than giving the receiving officer the authority to dispatch cars in uncertain situations or where the caller is insistent, the guidelines direct him to refer the call to his supervisory officer for disposition.

e. Guidelines with respect to misdemeanor assaults and threats of assault provide that if the officer determines that immediate medical attention is not required, and no further assault is imminent and the victim knows the identity of the assailant, then no car will be sent; rather, the complainant will be advised to report the incident to any precinct station. (It is not clear whether the effect of this guideline is that a car will be sent if the victim doesn't know the assailant's identity or that she simply will not even be advised to report the incident further.)

f. Guidelines concerning felonious assaults provide that a scout car will "normally" be sent unless the assault is not promptly reported and the complainant is not in need of medical attention and the reporting delay will not hinder the apprehension of the defendant, in which case the complainant should be advised as in simple assaults above.

g. Guidelines specifically directed to "family trouble" provide that such a situation "is basically a civil matter. It is not a police function to arbitrate or undertake negotiations in marital difficulties." However, if an assault is involved, the complainant should be advised as in other assault cases. But "if the caller does not wish to prosecute, other referrals may be made" to such service groups as AA, hospitals, legal aid, clergymen, or family service. (It would appear from this statement that, like a reported but unverified practice in Prince George County, Maryland, the switchboard operator may ask complainants in domestic disputes if they will prosecute; and if the answer is negative, not send a car despite the presence of all the factors necessary to send a car in assault cases. If this is not the policy indicated by this guideline, there is at least an ambiguity in need of clarification.) No escorts for persons securing their personal effects are to be provided because that is a civil matter.

h. Guidelines for "neighbor trouble" provide that disputes over property lines and like problems are civil matters; callers should be advised to consult an attorney.

\section{Diversion on Patrol}

In circumstances in which a car is dispatched, the typical patrol response emphasizes on-the-spot, temporary adjustment rather than arrest. There are many practical reasons for this approach. Frequently, the victim does not want the offender arrested. Arrest involvin' incarceration longer than overnight may result in the loss of the husband's job or at least temporary loss of support. Consequently, many victims may not be able to afford to have the offender arrested. In addition, arrest may anger the offender; and he may cause more serious harm to the victim upon his return to the family home. The officers themselves are influenced by the fact that victims quite frequently change their minds about arrest or prosecution after 
they have had time to cool off and that the court summarily dismisses "minor" charges stemming from domestic disturbances when the victim-complainant chooses not to prosecute. Accordingly, both courts and prosecutors tend to discourage prosecutions altogether or, in the case of the former, hand out lenient sentences. Naturally, these attitudes affect police policies and practices.

If the offender is not present, the responding officer may simply advise the victim of the warrant procedure or refer her to other relevant agencies and suggest she call again if the offender returns. Unless she pursues the warrant procedure or makes a subsequent call or unless the officer finds that her injuries are serious, the matter generally will not be investigated further. If she is in need of medical attention, he may take her to the hospital.

If the victim and offender are both present when the police arrive and the victim has not sustained serious injury, the police generally will attempt very brief mediation. This is often coupled with one or more of the following procedures: referral; threats of arrest or other forms of indirect sanctions; voluntary, temporary separation of the disputants; the threat of filing cross-complaints; and refusal to arrest except on a warrant. If the officers conclude, as is usually the case, that peace is at least temporarily restored through these actions, no further action will be taken on police initiative alon'e. ${ }^{12}$

In practice, an arrest is likely to be made only where one or more of the following factors is present in a domestic disturbance: serious injury, the possession or use of a weapon, the demand of a disputant to sign a complaint, an offensive attitude on the part of one of the disputants, a repeated call for police service, or the probability of a repeated incident or serious harm. Although an arrest is probably made more often than not when one of these factors is present, arrest does not follow as a matter of course. Naturally, when more than one factor is present the probability that an arrest will be made is increased..$^{13}$

Even if an arrest is made, it is a fairly common practice to release the offender in the morning with no further action taken unless the complainant presses for prosecution.

\section{III}

\section{InNovative Methods For Diversion}

\section{A. New Directions for Police}

Traditional police practice emphasizes short term adjustment almost exclusively. Mediation and referral are the only two, common police diversionary responses which relate to solving the underlying problems causing family conflicts. Consequently, increasing the effectiveness of these techniques offers the best opportunity, within presently accepted methods, for preventing repetition of similar or more

\footnotetext{
${ }^{12}$ Id. at $930-32$.

${ }^{13}$ Id. at 937 .
} 
serious incidents and thereby decreasing the involvement of police. However, until very recently, police training and guidelines on handling domestic disputes have been minimal or nonexistent. Instead, officers have been left to develop personal responses based upon their individual propensities and training passed to them from more experienced officers. Now, however, stimulated primarily by the Bard New York Family Crisis Intervention Unit project, many metropolitan departments include some domestic dispute-response training in their curricula; and a few departments are experimenting with special programs to handle domestic problems. These new programs are directed toward adjustments of family disputes that will be longer lasting than that produced by the methods formerly used.

\section{The Community Services Unit}

The Winston-Salem, N.C., Police Department's Community Services Unit (CSU), begun in 1966, was a forerunner in implementing some of the concepts of the Bard project and its progeny. Although broader and more sophisticated in function than the current community-service-officer trend, it emphasized similar objectivescrime prevention and community-assistance liaison. CSU encompassed much more than family disputes (notably, juvenile matters) in its experimental design and utilized essentially a social work, non-crisis, specialist approach rather than employing the generalist-specialist, crisis-intervention emphasis followed by the Bard project. $^{14}$

With respect to incidents of assaultive behavior, the role of CSU was that of follow-up rather than intervenor. The way in which CSU got its cases is uncertain. Apparently, problem finding was left to chance referrals and to the initiative of unit members. Although fairly easily remedied, this would seem to be a major deficiency. A better procedure would be to require non-arresting, intervening officers to report domestic disturbances to the CSU for a routine follow-up.

In Berkeley, California, the police department utilizes civilian, communityservice assistants for duties similar to those of the more formal Winston-Salem CSU. But in Berkeley, a patrolman may refer a family's case to the Community Relatons Division if he has had little success in helping a family suffering repeated domestic squabbles. A service assistant may be called to discuss the matter with the sergeant in charge of the division and sent to talk to the disputants. In' most

\footnotetext{
14 The CSU published a monthly newsletter, "Our Brother's Keeper," the bulk of which contained unit case histories. A particularly relevant case history from issue Number VI, p. 3, July r967, is as follows: "Mr. M. contacted a CSU officer and reported that he and his wife were having marital difficulties. After being married $2 \mathrm{I}$ years, Mrs. M. suddenly felt her marriage was unsuccessful and began seeking revenge for the unhappiness she felt her husband had caused. The results were a household filled with tension, two teenage children beginning to show the effects of strained relations, and family squabbles raging for days.

When the aid of a psychologist-counselor was suggested, Mrs. M. agreed on condition her husband would attend the sessions. His response was favorable and counseling has been arranged.

The couple has just returned from a recommended vacation together, which proved to be a success with both partners agreeing to rebuild their marriage. The children have reported to CSU officers a much improved home situation and reconstruction of a stable family life."
} 
cases this visit occurs within two days of the incident. He discusses the problem with the disputants; but his main purpose is to decide if referral is advisable. If it is necessary, the community-service assistant makes an appointment for the family with the proper social service agency. Under normal circumstances, the appointment will be within one or two weeks; however, in an emergency the Community Relations Division will arrange for the disputants to receive immediate aid from the given agency.

\section{The New York Family Crisis Intervention Unit}

Programs such as those in Winston-Salem and Berkeley raise basic questions which must be answered before their effectiveness can be evaluated. Assuming the need to intervene and follow-up, a decision must be made as to who will intervene initially in a dispute, who will follow-up this primary contact, and what forms intervention and follow-up will take. A training program must also be planned to instruct the personnel who will be involved in helping the family-both in initially stopping violence and in preventing future incidents. The Family Crisis Intervention Unit (FCIU) in New York is a major attempt at dealing with these elements.

FCIU has been cited by the National Commission on Civil Disorders as a program of special interest; it was designed to improve police performance of their service function. Fun'ded by the Law Enforcement Assistance Administration, its major objective was to demonstrate the potential for crime prevention and preventive mental health that exists in training selected police officers as specialists in familycrisis-intervention techniques. Police officers were trained to function as subprofessional, mental health workers; but the intent of the project was not to convert the officers into social workers or psychotherapists. Rather, the purpose of the training was to increase their effectiveness in the characteristic police role of preventing violence. ${ }^{15}$

At the outset, nine black and nine white patrolmen, selected from a group of volunteers for their interest, motivation, and aptitude for family crisis intervention work, received one month of special training. This training period was concluded with three especially written plays portraying family crisis situations. The officers were asked to intervene in these situations and thus were exposed to the variety of outcomes which may result from different forms of intervention. Continuing, in-service training beyond this initial period was conducted under professional leadership and was regarded as an essential aspect of the over-all effort.

Following the initial training period, the men were assigned to the Thirtieth Precinct which covers a multi-racial area of West Harlem. The family crisis unit functioned in nine bi-racial teams separated into three groups. One group was assigned to each eight hour watch. A single team manned the unit's car and

\footnotetext{
${ }^{15}$ Parnas, The Response of Some Relevant Community Resources to Intra-Family Violence, 44 IND. L.J. I78-79 (rg69).
} 
was dispatched to all complaints which were predetermined by the dispatcher to involve "family disturbances." The two remaining teams provided back-up service in case of multiple calls. When not handling family matters, the unit's car performed normal patrol functions. All family disturbances within the precinct were ordered to be handled by the unit's personnel.

The relation of the FCIU experiment to the diversion of intra-family violence cases is, at least in theory, quite significant. The FCIU concept employs preventive mental health training, intervention techniques, and related administrative procedures in an effort to resolve more disputes than would be the case under the traditional response of temporary restoration of order. Where temporary maintenance of order, rather than resolution, is the objective and all the parties and circumstances of the conflict remain together and basically unchanged, the effect of that intervention on the source of the conflict is slight. Once the coercive effect of that intervention dissipates, the conflict may erupt again, perhaps with increased intensity (increased, perhaps, because of the fact of intervention itself).

Domestic disturbances are not substantially diverted from the police process when the same family makes repeated calls for help; the offender must ultimately be arrested because temporary intervention has not deterred him; or the offender, by inflicting a serious wound or committing a murder, invokes the lengthy criminal processes which follow a felony. Under the traditional approach of temporary adjustment, these are common results. The FCIU attempts to remedy this failure to divert by equipping its policemen with the increased incentive, knowledge, insight, and skills necessary to effectively respond to and divert family violence. Domestic problems can be deemed to be significantly diverted from the criminal process only when the result of a police service call is not only restoration of order but activation of a process which at least has the potential to resolve the source of the conflict.

The success of FCIU in its goal of prevention is not yet clear. A final evaluation will be reported early in 1972, in conjunction with the final report on a related project which was designed to build on the FCIU experience and to provide answers to some of the questions which the original project was unable to supply. ${ }^{16} \mathrm{~A}$ number of methodological limitation's prevent firm assessment of the impact of FCIU. Chief among these are difficulties in evaluating the performance of the FCIU precinct in comparison to a neighboring, roughly similar precinct selected to

\footnotetext{
${ }^{10}$ Bard's second phase project utilized the I400 man Police Department of the New York City Housing Authority. Groups of recruits and experienced officers were subjected to different modes of training for conflict resolution and police work. The separate groups were then assigned to work within different projects so that comparative results could be obtained. For further descriptions of this project see, Bard and Zacker, Design for Conflict Resolution, mimeograph of address presented to the 3rd National Symposium on Law Enforcement Science and Technology, Chicago, April I, 1970; Bard, Training Police as Specialists in Family Crisis Interventions, FINAL Report to LAw ENForcement Assistance AdminIstration, May, I970 (U.S.G.P.O.-704); and Interim Report to LEAA, Police Management of Conflicts Among People (August, 1970).
} 
provide a comparative base. During the FCIU program, the problem of disparate motivation between the FCIU precinct and the comparison precinct was perceived and did affect evaluation of results. Stated simply, in drawing comparisons it is difficult to separate real effects of FCIU from random variations in the two precincts or, more importantly, from administrative and records-keeping changes growing out of the new emphasis upon handling domestic disputes within the FCIU precinct.

Some examples from the data that is available illustrate these evaluative difficulties and provide a description of the functioning of FCIU. Differences in recording practices are one problem. During the first twenty-two months, the FCIU precinct intervened on 1388 occasions involving a total of 962 families. On the other hand, although selected for its apparent similarity to the FCIU precinct, during this same period the comparison precinct recorded only 492 interventions with 484 families. According to the project staff, "One possible explanation [for this unexpected] difference could be the motivation to record incidents as they occurred."17 Similarly, while $30.7 \%$ of all FCIU cases involved situations in which the unit had previously intervened, only $13.8 \%$ of the comparison precinct interventions were repeats. Although this might appear to suggest that FCIU did not perform as well in avoiding future trouble as did the traditionally practicing groups, the higher recidivism of FCIU may merely reflect its increased attention to family disturbances or its more rigorous data collection which would reveal a more accurate estimate of family disturbances than was available through traditional recording practices.

On the other hand, the availability of a more effective police service in this connection may have resulted in greater and more effective community utilization of the FCIU. ... . However, the tendency for the 3oth Precinct [FCIU] to have a smaller percentage of "once only" interventions may be mute testimony to the unreliability of comparison precinct data. That is, if initial cases went unreported and the same families were later visited, they would erroneously be reported as initial cases rather than as repeats. ${ }^{18}$

The comparative data with respect to the incidence of homicide and assault are also inconclusive. In any event, it may be unrealistic to expect immediate and observable effects with respect to assault and homicide rates. Homicides increased three and one-half times in the FCIU precinct during the twenty-two month operational phase as compared with the immediately previous twenty-two month period which showed an increase from twelve to forty-two homicides. Although there was a city-wide homicide increase during this period, inexplicably there was a one-third reduction, from forty-eight to thirty-two, in the comparison precinct. Family homicides increased from one to five in the FCIU precinct and yet stayed

\footnotetext{
${ }^{17}$ Bard, supra note $I 6$, at 25 .

${ }^{28}$ Id. at 27.
} 
constant at two in the comparison precinct. However, two of the five victims were transients and not residents of the FCIU precinct at the time of the slaying, and none of the five families had previously been visited by FCIU. It is not clear whether the two families involved in the comparison precinct slayings had previously been known to the police; and, in any event, the numbers of family homicides in either precinct are too small for valid analysis.

Assaults in the FCIU precinct show a slight increase over the previous twentytwo month period, while the comparison precinct shows a decrease. During the prior period, no breakdown of family assaults was kept; thus, a before-after comparison cannot be made. However, during the term of the project, family assaults were one-third more frequent in the comparison precinct than in the demonstration precinct and comprised about $19.5 \%$ of total assaults in both precincts. Arrests for assault in family disturbances were slightly less $(2.5 \%)$ in the demonstration precinct than in the comparison precinct. Again, the significance of these data is diffcult to interpret because there is no assurance of uniformity of reporting. The project staff, however, notes that "there is the suggestion that the FCIU may have maintained a lower arrest rate in family disputes through the use of mediation and referral techniques."19

In the early months of the project FCIU teams were inclined to make an excessive number of referrals due, perhaps, to insecurity about their role and unrealistic expectations about agency potentials. Later, disenchantment with the referral agencies developed; and the unit members began to rely more on their own mediative skills. In the words of the project report:

What appeared at the outset to be one of the most promising features of the project proved to be one of its most consistent frustrations. The officers were delighted to learn of the variety of social resources available in New York City and they started out making many referrals. But ... the realities ... [are that] the agencies are geared to serve the middle class who will travel to the office, go through an application process, accept and keep appointments, sometimes after long waiting periods. ... With minor exceptions, the agencies could not [would not?] adapt their policies and practices to the demands made on them by FCIU.20

Nevertheless, during the initial twenty-two months $75 \%$ of all families were referred somewhere by $\mathrm{FCIU}$ as compared with $55 \%$ referred in the comparison precinct. In addition to a higher rate of referrals, a greater selectivity in referral agency choices by FCIU is suggested. Thirty-five per cent of the families referred by FCIU were referred to the Family Court; whereas, $89 \%$ of the comparison precinct's referrals were to the Family Court. In part, this may have resulted because fewer local agencies were available to the comparison precinct. However, FCIU generally made more referrals to the resources available to both precincts, that is, to other public agencies and hospitals.

\footnotetext{
${ }^{10} \mathrm{Id}$.

${ }^{20} I d$. at 20.
} 
On the basis of the information returned by the referral agencies, of the 346 families on whom information is available, only $20 \%$ of all families referred actually applied for assistance at the recommended agency. Completed referrals were most frequent when concrete services were expected of the agency [e.g., hospital $(50 \%)$ or welfare agency (67\%)]. ${ }^{21}$ Only $26 \%$ appeared at the Psychological Center, and only II $\%$ of $2 I_{4}$ FCIU referrals made their application to the Family Court. The disappointing rate of completed referrals may cause underestimation of the effectiveness of FCIU in directing disputants to other resources. Data was collected by use of a referral follow-up form, and there may have been some failure to record referrals which were actually completed. It "was difficult to ascertain whether clients were not acting on referral recommendations or whether the agencies were being remiss in responding to the inquiry."22 Follow-up visits to determine outcomes of police contacts (in both precincts) for purposes of assessing the effectiveness of referral as well as violence-prevention variables were precluded by police department policies based on a "concern for the civil and individual rights of the families visited by the police."23

A more definite positive result of the project is indicated by the data concerning the risk of harm to the policeman-intervenor in family disputes. Although FCIU was exposed to a greater number of family disputes, no injuries were sustained by members of the FCIU, while two demonstration precinct patrolmen and one comparison precinct officer were injured handling family disputes during the period of the project. Some other favorable impressions reported are community approval, retention of police identity by members of the FCIU, and acceptance of the FCIU by their police colleagues. Due to the inherent lack of control of variables when the community is the laboratory, obtaining scientific findings is difficult, if not impossible. Perhaps an evaluation of the goal sought, efforts expended, and resulting staff and community impressions is the best that can be expected. In these times, any government activity-particularly police activity-which fosters communityespecially ghetto-acceptance and approval should be carefully examined before it is discarded.

The status of FCIU following the termination of the federal grant has been uncertain. Citations for FCIU members as well as further implementation of the concept, in modified form, in five other precincts were suggested to the department. Citations were refused on the grounds that the unit members were just doing what any good officer would do. ${ }^{24}$ The second suggestion had been totally ignored as

\footnotetext{
${ }^{21}$ Id. at 30-32.

${ }^{22} I d$, at 10.

${ }^{28}$ Id. at 7 .

${ }^{24}$ It may well be true that all officers should deal with family disturbances as the FCIU did. However, all available data indicate that it is doubtful that most policemen view their function in such a light. In any event, whether they do or not, a basic tenet of psychology is that rewards for good work done often provide the necessary incentives for further good work by the same and other workers in any field.
} 
of October I970. In fact, the department had also totally ignored the FCIU unit itself since the project terminated. They were not told whether to continue to operate as before. Thus, the unit continued in a vacuum; and several members eventually transferred out. The remaining officers tried to man the FCIU car whenever they could. It is said that the project was implemented at a politically opportune time and was not expected to succeed. Accordingly, we may assume that changing political winds and governmental inertia account for the program's demise.

In general, the only implementation on the local level that has occurred has been the reformation of recruit training to include instruction on crisis intervention: The project report predicted this possible reaction in its section on "Implementation and Institutionalization":

If past experience is any guide, there will be a tendency to legitimatize family crisis intervention as a police function by curriculum insertions in present training programs (recruit and in service) [as has been the case in Washington, D.C., for another example] and by developing a "how-to" instructional manual. Such an approach, while both predictable and understandable, represents a rejection of the basic contribution of the present demonstration. What is more, it implies the illusion of change where no change in fact occurs. ... [R]egardless of the awesome complications involved, the validity of the demonstration effort can be maintained only if its integrity is preserved.

The approach undertaken in this project demonstrated a viable method for accomplishing collaboration between professionals in law enforcement and in mental health. Usually operating in mutually exclusive isolation, these two groups have, in this project, demonstrated the capacity to collaborate successfully to their mutual advantage and to the advantage of the community as well. For each to retreat to traditional positions of isolation violates one of the most vital aspects of the demonstration. The measure of the demonstration's effectiveness will be reflected in the extent to which such collaboration continues.5

\section{The Impact of FCIU}

Despite its currently uncertain status, FCIU has had a phenomenal influence upon the activities of police departments throughout the United States. Louisville, Kentucky, has come the closest to an actual replication of the New York FCIU project, although its effort is on a much smaller scale, involving approximately twelve patrolmen. ${ }^{26}$ The idea has even filtered down to the small department in Redondo Beach, California, which developed a program to give officers FCIU-type training. The Oakland Police Department recently instituted a Family Crisis Intervention program for an experimental period of six months. The program was inspired by the New York project but was also a reaction to the discovery that domestic disputes placed a heavy burden upon the time and resources of the average patrol-

\footnotetext{
${ }^{35}$ Bard, supra note I7, at 33-34.

${ }^{20}$ In the very comprehensive and enthusiastic Final Report, Police Training in Family Crisis Intervention (Sept. 30, 1971), the Louisville project is described in detail, results are stated and compared with the New York FCIU, and many of the findings of that basic program are reaffirmed.
} 
man. A pre-program study made of the six-month period between January and June of $x 970$ showed that Oakland officers responded to more than 16,000 family disturbance calls necessitating an expenditure of more than 8,000 man hours. Approximately twenty-five per cent of these disturbances were return calls, and most occurred between 7 p.m. and 3 a.m. on Wednesday through Sunday.

The basic program philosophy in Oakland is one of problem-solving with an emphasis on referral, rather than arrest and prosecution. More specifically, it is concerned with improving police capabilities of restoring order in a family crisis, assisting families in resolving the tensions which cause disputes by referring them to appropriate agencies, minimizing further police involvement by providing solutions before serious injury results, establishing a liaison between police an'd other community service agencies, enhancing police-community relations by making more competent services available to the community, and freeing officers for other police activities by decreasing the number of family disturbances to which they must respond. ${ }^{2 \tau}$ Preliminary statistics after the first twelve weeks show only seven return calls out of 242 handled initially and only five arrests.

There are two field units in the Oakland program; each is composed of two patrolmen. Each unit is assigned to one of the major areas in the city from which a large percentage of domestic dispute cases originate. They patrol their assigned areas in unmarked vehicles from 7 p.m. until 3 a.m., Wednesday through Sunday. The primary emphasis is placed on handling family disturbance calls, and a secondary concern is with answering other disturbances-of-the-peace calls, emergency dispatch assignments, and preventive patrol. A Family Disturbance Form is completed for every call handled. One copy is placed on file with the FCIU Staff Coordinator, and the other copy is kept in the patrol car of the field unit that handled the call. The main function of this form (like that of the FCIU) is to provide a reference in the event of a return call. If the unit is called a second time, it can easily determine how the case was disposed of previously. If a referral was made before, the unit attempts to discover why it failed.

Initially it was within a field-unit officer's discretion either to refer the disputants directly to a social service agency (with which prior arran'gements for cooperation had been made) or to direct them to call the Oakland FCIU staff coordinator to make an appointment for them. In either case, a card was filled out by the patrolman giving the disputants a telephone number to call for an appointment. This field choice, however, has been changed, and all appointments are now made through the FCIU coordinator. When it was left up to the disputants to make the appointments, often they would not do so. For example, only twenty-six of seventy-two referrals in the first twelve weeks were reported to have completed their appointments. If referral was completed, disputants often failed to inform

\footnotetext{
${ }^{27}$ Oakland Police Department, Information Bulletin-Family Crisis Intervention Program, Jan. I8, r97r.
} 
the agency that they had been referred there by the FCIU. A failure to so inform usually meant a longer waiting period before the agency took action. After making the appointment, the coordinator informed the disputants of the time and place. By following this procedure the persons involved could usually speak to an agency social worker within one or two weeks. Such police involvement in the appointment process is likely to motivate the disputants to keep the appointment, but ir lends a coercive element to the treatment which may hinder its effectiveness.

The only formal follow-up done by the Oakland FCIU is through questionnaires, although occasional informal personal follow-ups by unit officers occur. Onice the appointment is made, a questionnaire is sent to the agency to be answered and returned after the disputants have been seen. Another questionnaire is sent to the disputants following their first contact with the referral agency. The main purpose of both questionnaires is to measure the level of effectiveness of referrals made by the FCIU. ${ }^{28}$

Officers in the Oakland Unit, instead of receiving one month of intensive training before entering the field, received only a one-day seminar with representatives of social service agencies involved in the program. Oakland believed that the New York unit's extensive training was unnecessary. Instead it relies on the good judgment and experience of unit members. To offset any detrimental effect of lack of specialized training, unit members were selected on the recommendation of their peers, were interviewed, showed prior capability in handling domestics, and showed present willingness to be a part of the unit. All of these factors were also used by the Bard project to select those individuals who then underwent the month's training.

${ }^{28}$ Although referral follow-up of some kind would seem to be essential both from the standpoint of evaluation and adequacy of response, the propriety of the circulation of a counseling agency's comments - particularly if called for by a law enforcement agency-may be seriously questioned. A lack of confidentiality in the treatment process may be a deterrent to the effectiveness of the consultation as well as an actual (if not legal) infringement on the clients' right of privacy. The Oakland Agency follow-up questionnaire seems to raise such questions.

Agency Follow-Up Questionnaire

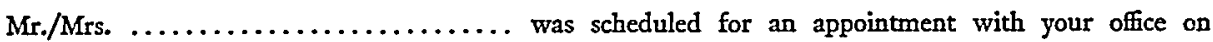
................................ at $/ \mathrm{pm}$.

I. Did the party appear for the appointment as scheduled? Yes ...... No ........

If no, what follow-up action has your agency taken to ascertain if further assistance is necessary?

If follow-up by your agency was negative, can the Family Crisis Intervention Program be of further assistance?

If the appointment was kept, does it appear that the Family Crisis Intervention Program made a proper referral or should the party have been referred to another agency?

2. In addition to the services provided by your agency, is there an additional need for services in which the Family Crisis Intervention Program could be of assistance?

In your opinion, will the party benefit from the services of your agency? Please explain your answer!

3. Briefly state the nature of the assistance you have provided and what, if any, follow-up or continued services you will be providing in the future.

4. Have you received any favorable or unfavorable response from the party regarding the operation or services of the Family Crisis Intervention Program? Please explain! 
A second important difference between the New York and Oakland programs is that in Oakland, although officers meet frequently for self-evaluation, they apparently do so without the aid of a professional to direct them. However, each call to which the unit responds is recorded on a small tape recorder attached to the responding officer's belt. These tapes undoubtedly are extremely helpful in the self-evaluation sessions, but the propriety of the use of such a device should be seriously considered.

Other departments have responded to the New York model by instituting training procedures similar to those developed by the New York FCIU project. One of the most extensive of such efforts is in: Multnomah County (Portland), Oregon. These officers participated in an eleven week course (including four evening meetings, three hours in length and a five day seminar, forty hours in length) and receive upper-division college credit. The program includes lectures, seminars, discussions with mental health professionals concerning actual and simulated crisis interventions and problem cases, sensitivity training films, follow-up meetings after completion of training, and on-the-job observation by the professionals. The objectives of the project are:

I) To train the general patrol force in basic domestic disturbance control techniques;

2) To provide post-crisis psychiatric counseling and assistance to families in need of further care;

3) To provide systematic referral services and follow-up between families involved and the appropriate assistance agencies;

4) To provide a coordinated effort, utilizing graduate students and behavioral science specialists in family disturbance and general mental health activities within the community; and

5) To provide on-going mental health consultation and training for Domestic Disturbance Specialists. ${ }^{28}$

An ambitious project has recently been started in Tacoma, Washington. Its most innovative element is placing mental health professionals with patrol units. These professionals actively participate in the handling of the disputes. Subsequent contact by a clinical staff is made to assess whether intervention and referral have been effective. A major objective of this project is to lay the foundation for the eventual removal of these situations from police management. No data is yet available to describe how well this program functions.

\section{B. Joint Police-Prosecutor Methods}

At the charging level, diversion of domestic complaints may be accomplished by joint police-prosecutor screening structures. For example, Detroit's Misdemeanor Complaint Bureau (MCB)-located in police headquarters and staffed entirely by plain-clothes detectives-holds informal hearings under the general supervision

\footnotetext{
${ }^{29}$ Application for Law Enforcement Action Grant.
} 
of the district attorney. ${ }^{30}$ The Bureau has informal jurisdiction over assaults and batteries which did not result in serious injury and occurred between relatives, intimates, or neighbors. Less frequently, it also handles cases of malicious destruction of realty and personalty, larceny from the person, indecent language in presence of women or children, and entering without permission..$^{31}$

Victims desiring prosecution are instructed by Detroit patrolmen to appear at the appropriate precinct detective bureau the following morning. Complainants appearing at the precinct to request a misdemeanor warrant complete a complaint form and are instructed to present the forms to the MCB. Reportedly, little screening occurs at the precinct level (although it is desired by MCB) except for that accomplished by requiring the complainant first to come to the precinct to secure the warrant request forms and then to go to the centrally located MCB to obtain further processing. ${ }^{32}$ Initial interviews, offender notifications, an'd subsequent informal hearings, to which both parties are allowed to bring witnesses and necessary evidence, are all handled by detectives. In addition, the final disposition by the detectives is somewhat unique; "adjournment without date" or the placement of one or both parties on a non-existent, non-secured, verbal "peace bond" is usually what occurs. The MCB also has a court sergeant who handles any MCB cases coming before the Recorder's Court which have not been diverted by the process. The MCB's six detectives handle 400-600 requests for warrants each month. About two-thirds of the parties are said to appear for the hearings. Most requests do not result in a warrant. During the first ten' months of 1970 , out of a total of 5057 warrant requests, 323 resulted in the issuance of a warrant. ${ }^{33}$

${ }^{80}$ The less comprehensive, but nonetheless interesting, joint walk-in complaint operations of Philadelphia and Washington, D.C. are described in the larger ABF article cited in the introductory note.

${ }^{\mathrm{ax}}$ For other published accounts of the operations of the MCB, see D. MCINTYRE, LAw ENForcement IN THE METRopolis I03 (1967); Parnas, The Police Response to the Domestic Disturbance, I967 Wisc. L. Rev. 945. See generally W. LaFave, ARrest (I965); D. Newman, Conviction (I966).

${ }^{82} \mathrm{~A}$ major justification for the $\mathrm{MCB}$ is the savings in time, and therefore money and protection, provided by not requiring detectives from all the precincts to go to the prosecuting attorney's downtown office for warrant determinations, as they apparently must do in all others. For example, monthly estimates of "miles saved" reveal that 3,826 hours were saved in December, r968; the yearly savings total was $69,93 \mathrm{r}$. It might be asked, however, whether the screening in the precincts would not tighten up considerably if officers were required to appear at the prosecuting attorney's office.

\begin{tabular}{|c|c|c|c|c|c|c|}
\hline \multicolumn{7}{|c|}{ MISDEMEANOR SECTION } \\
\hline DATE & WARRANT & PEACE & CRTP & WARRANT & WARRANT & PRCT CASES \\
\hline 1970 & REQUEST & BOND & & & DENIED & TO COURT \\
\hline Jan. & 449 & 67 & I8 & 38 & 326 & 289 \\
\hline Feb. & 420 & 65 & 7 & 20 & 328 & 390 \\
\hline March & 450 & 75 & 45 & 25 & 305 & 483 \\
\hline April & 446 & 86 & 40 & 24 & 302 & 447 \\
\hline May & 576 & IIO & 45 & 23 & 393 & 420 \\
\hline June & 606 & II 8 & 20 & 25 & 443 & 545 \\
\hline July & 547 & 123 & 16 & 28 & 380 & 590 \\
\hline August & $59 \mathrm{I}$ & 160 & 45 & 56 & 330 & 638 \\
\hline Sept. & 544 & 132 & Ig & 58 & 335 & 629 \\
\hline Oct. & 428 & 90 & 23 & 26 & 288 & 555 \\
\hline
\end{tabular}


ConcLusion

"Presumably, an important test of a good society is how much preventable real trouble it removes from the shoulders of its citizens, and, after that, how rapidly and effectively it marshals what it knows to repair the damage done by nonpreventable trouble."34 By this definition, ours has surely not been a "good society" with respect to preventing the very "real trouble" of neighbor and domestic disputes or marshalling its knowledge an'd resources "to repair the damage done" by those disputes not prevented, and much less with respect to doing this "rapidly and effectively."

Subin very concisely summarized the problem with the traditional, criminalprocess response to matters of intra-family and neighbor violence:

[O]f all of the areas in which an alternative to criminal treatment seems justified, the area of marital disputes is the most obvious. This is not to say that violence, theft, or neglect between spouses should be ignored, but it does appear that these cases deserve different treatment than they are now given. Whether prosecution is decided upon or not, it would seem that beyond the point of immediate police response in danger, the criminal process is largely irrelevant in these cases. If anything, its very invocation may exacerbate poverty-related and/or psychological problems. The summary, rather shallow treatment given these complaints does not answer the need that they have expressed for help. ${ }^{35}$

As we have seen, however, the traditional response is slowly being eroded by innovation and experimentation. However, innovation at only one stage of the criminal process, as is usually the case, without recognition of the interaction of agencies within the process limits the breadth of the project and its problemsolving potential. Without a good faith commitment to continue and to broaden the effect of successful projects, experimentation is not only a frustrating experience

\section{Explanation:}

Warrant Request-Number of persons who came into bureau with writeups from the various precincts as a result of making a complaint either to the patrol officers or to the precinct detectives.

Peace Bonds-In Detroit, a "Peace Bond" is not enforceable. It amounts to a warning to the defendant (sometimes also to the complainant) to live in peace. A violation of a "Peace Bond" indicates that a court should hear the case.

Complainant Refuses to Prosecute-A situation in which the "cooling off" period, the healing of the bruises and the resumption of peaceful relations has abated the complainant's anger.

Warrant-Cases in which a warrant is issued. If the defendant is in custody, the case goes immediatetly to court. If the defendant is later arrested, the complainant is contacted and advised to be in court on a specific date, usually the day after the arrest.

Warrant Denied-A warrant is denied officially by a Prosecutor. [No evidence of any such procedure by a District Attorney was found unless it was pro forma.]

Precinct Cases to Court-These are misdemeanor cases that the precinct officers present to the officer from our Bureau who is assigned to court. The Precinct Officer or Detective is freed then to resume normal duties if:

I. He is not a witness.

2. The case does not include gun violations.

3. There is no obvious need for his testimony.

${ }^{34}$ E. Koos, Families iN Trouble vii (1946).

${ }^{35}$ Subin, supra note $\mathrm{T}$, at 56-57. 
for the experimenters but also a tremendous waste of limited human and financial resources. Intra-family violence is a significant problem; alleviating it is an important goal. Therefore, we must be willing to appropriate the necessary resources promptly and on a continuing basis if we are genuinely concerned with easing this social problem. Because of our limited expertise in behavioral sciences and our inability to make scientific evaluations of in-field experiments, promising projects have been allowed to die. This trend must be reversed; recognition of these limitations should be a stimulus to imaginative, lengthy, community experimentation where even tentative and highly impressionable results seem to have positive potential.

There are several common elements present in those experiments which seem to offer the best hope for effective diversion of family violence incidents by incorporating essential problem-solving techniques in their approach. A primary ingredient, not only in police innovations but in prosecutor an'd court experiments as well, appears to be the involvement of a variety of people who are not traditionally considered to be part of the criminal process. Indigenous lay personnel, college students, professional social workers, psychologists, psychiatrists, and others should be involved in varying degrees. The categories of related, criminal-process activities in which this kind of personnel are becoming involved are increasing. They include positions contributing input in police recruit selection; preparation' of police training curriculum; personal police recruit training; personal reinforcement and followups and subsequent assistance to disputants; on-the-spot, stationhouse, referral services; emergency social services in addition to or as an alternative to a police response; referral and problem-solving services related to complaints and warrant requests made to the prosecutor; pre-trial problem solving and referral services on the court premises; exclusive, original jurisdiction in a non-criminal, problemsolving directed court system; utilization of the relevant quasi-judicial processes of arbitration and mediation; and active cooperation by external agencies with the police, prosecutor, and courts on referrals. The creation of such activities and the involvement of lay personnel in them supplements manpower of overburdened criminal process agencies. It adds some of the problem-solving time and expertise necessary to divert cases in a manner that offers a reasonable chance that a significant number will not simply reappear shortly thereafter.

It is difficult to devise a practical way for the police to avoid initially responding to dangerous family situations. (Although the Tacoma-Pierce County, Washington, project mentioned earlier apparently aims at this goal.) Nevertheless, development of dispatcher screening and information gathering, and patrol referral policies is urgently needed. Implementation of FCIU training alone, as a number of police departments have done, is insufficient and creates the illusion of change where no significant change in fact has occurred. Continuing, as well as initial, collaboration between law enforcement and mental health professionals was an essential feature of the New York experiment. 
If the prosecutor's office remains in the official process of dealing with domestic and neighbor dispute walk-in complaints, it would seem preferable to use non-police connected personnel in this capacity. There is no question that police-staffed units temporarily divert significant numbers of cases. However, the decision' to charge or not is best made by a prosecutor, not a policeman. If the problem requires an informal "hearing" with legal advice given and the threat of future prosecution brought to bear on the offender, this, too, would be more properly done by a prosecutor. And if the prosecutor's decision involves some counseling or referral, the advice could best be given by someone in the social services.

The plain clothes detectives in the MCB hearings are often mistaken for prosecutors. Sham peace bonds are frequently imposed, and disputants are said to refer to the detectives as "judge." Neither the disputants, the police officers, nor the governmental process should be put in such a fictitious position. Not only the appearance, but the reality of propriety could be restored by a revival of Washington, D.C.'s Citizen's Information Service, an adjunct to the prosecutor's office, or the creation of a unit within the structure of the prosecutor's office staffed by social service personnel, such as San Francisco's Family Relations Bureau.

But the prosecutor, unlike the policeman, need be involved only minimally with domestic disputes if a family court which includes family offenses is implemented in his jurisdiction. Besides being a clear diversion out of the criminal process, the family court utilizes problem-solving professionals and techniques necessary to have a reasonable chance at preventing repeated or increased violence within the police, prosecutor's and criminal court's jurisdiction. New York's Family Court involves a prosecutor only if a case is transferred out of the Family Court as inappropriate for its proceedings. Accordingly, the N.Y. Family Court, particularly the generative Manhattan branch, should be very carefully considered by any jurisdiction seriously interested in significantly diverting matters of intra-family violence at least away from the prosecutorial and criminal court stages of the criminal process, if not ultimately the police stage as well.

In addition to the family court, a Philadelphia experiment embracing referrals for arbitration and mediation by trained, private personnel is also a noteworthy innovation. However, it may prove most useful in resolving matters amenable to a quickly-reached settlement, such as consumer fraud cases or even neighbor disputes. In domestic disputes, underlying causes are sometimes deep and subject to continual eruption because of the close, emotional contact of the parties. They need the intensive treatment of the social services which the adjunct agencies of a family court can at least begin to give.

A virtually untapped source of assistance in most instances of intra-family violence is the conciliation court which is becoming more prevalent in various parts of the country. Enabling legislation as well as court procedures should make these professional counseling services available at the first signs of potential family 
dissolution. Police and prosecutors should be aware of this referral resource and the conciliation court should be aware of the law enforcement agencies as casefinding sources.

Unfortunately, the best that can be said about the criminal courts' approach to family disputes is that these courts rarely incarcerate domestic disputants. Among the worst aspects of their approach are the lack of attempts at problem solving and the frequent use of utterly improper, although well-motivated, dispositions, such as the Chicago peace bond. Nevertheless, experimentation is desperately needed with modified or new court structures and procedures. In some cities, for example, there has been some quasi-official experimentation with panels of minors as judges in juvenile cases. On a slightly different front, rabbinical and ecclesiastical courts still exist behind the scenes and appear to exercise some influence over their select litigants. Such bodies bring to their cases a different perspective for both court and litigant which might prove to be beneficial to the similarly more personal and less anti-social domestic and neighbor conflict.

Innumerable possibilities exist if only imagination and creativity are encouraged. For example, a panel, consisting of three laymen or two laymen and a lawyer, all indigenous to and selected by the neighborhood or housing project over which it has jurisdiction, holding evening hearings in a local clubroom, and utilizing local talent in its dispositions, could be established to handle family and neighbor disputes. The presumed heightened actual and apparent cultural understanding and peer group pressure would be the major distinguishing features of such a process. Although questions of authority, jurisdiction, procedure, sanctions, and enforcement are immediately apparent, actually inertia is the only real stumbling block to new and worthy ideas. Once inertia is overcome, it is amazing how quickly the seemingly monumental procedural questions can be readily worked out and an idea given a chance.

A comprehensive scheme for effectively handling domestic disputes would not be complete without mentioning the concept of initial prevention. Up to this point, all of the methods we have considered deal with trouble which has already occurred. Yet, initial prevention would be the best possible diversion. Such controversial movements as honest sex and family education in our schools, effective encouragement of pre-marital counseling, and recognition of trial marriages might aid in the spouse selection process, help to prevent the sources of some domestic conflict, and prepare spouses to cope with inevitable conflicts in a non-violent way. But important as these things are, given discrimination, unemployment, ${ }^{36}$ poor housing, insufficient

\footnotetext{
so "A bored man is a potentially violent man, claims Dr. Rober Tredgold, a British specialist on psychological medicine. And statistics in the city of Birmingham (England) seem to bear him out. For the past six months an increasing number of Birmingham wives report that their husbands have taken to beating them. Black eyes, bruised faces, twisted arms-such is their lot in life.

Why is the wife-beating problem on the increase?

'Many cases stem from the frustrations and tensions in homes where the men are unemployed,' reports
} 
food, and harrassment-the innumerable deprivations, frustrations, and rejections of the poor and ignorant-it would seem reasonable to surmise that intra-family violence will continue to abound as an outlet for these pent-up alienations.

On the other hand, it apparently isn't all that clear that the poor are any more violent than the middle-class. In fact, Sociology Professors Stark and McEvoy of the University of California, commenting on the results of their survey for the National Commission on the Causes and Prevention of Violence, indicate, among other things, that one-fifth of their national sample approved of wife slapping "on appropriate occasions." "If anything, the middle class is more prone toward physical assault (punching, beating, slapping) than the pcor." What does appear to be clear, however, is that poor domestic disputants tend to become involved in the criminal process more frequently than others. It can be argued that middle class status, education, and financial resources militate against the involvement of police and subsequent criminal processes in family affairs and towards utilization of friends, professional coun'selors, separation, or divorce. Ironically, the policeman, ${ }^{37}$ despite the frequently expressed hostility towards him, is the poor person's first port of call in time of trouble. Whether or not more domestic disputes occur among the poor, more of the poor do become involved in the criminal process as a result of their socio-economic situation. Thus, to significantly prevent their domestic disputes from occurring or coming to the attention of the criminal process, either of which would be diversions, the characteristics of their socio-economic condition must be modified.

The ultimate conclusion in this analysis is the same as that of so many recent and not so recent Presidential Commissions-a rechannelling of priorities and a real

a spokesman for the Birmingham Citizens Advice Bureau. It has gotten so bad that we are thinking of setting up a small hotel where wives can get away from it all for a little while.'

Unemployment is at its highest level in Great Britain in more than a decade, and apparently wife-beating goes hand in hand with unemployment. Frustrated, bored, unable to find a satisfying outlet for their energy, Britishers who are reduced to life on the dole meet adversity like men: they blame it all on their wives. Then, pow!!!" Sacramento Bee, Parade Magazine (circa. Sept.-Nov. I97I).

${ }^{87}$ The all too obvious potential for utilization of policewomen in responding to domestic disturbances has long been overlooked. Recently, however, some departments have been broadening their patrol use of policewomen, perhaps with an indirect push from the current women's liberation movement. For whatever comfort it may be, the male chauvinist may nonetheless have some support for his arguments because it appears that the policewoman's differences may allow her to better respond to these incidents than her male counterparts. It has recently been reported that:

"In an effort to be more effective at peacemaking, an increasing number of police departments are now trying a new strategy. They are sending policewomen to do what was once strictly a male cop's job. The reason: women seem to calm these disputes far better than men. 'Some of these families will call you back two or three times a night,' observes a battle-tested Indianapolis patrolman, 'but I've noticed that when the women go, that's the last time we hear from that family. . . . In the family quarrel, ... male officers 'feed the fire through their own aggressive, provocative behavior,' says Lewis J. Sherman, a University of Missouri-St. Louis psychologist who studied the activities of security guards in eight St. Louis housing projects last summer. Women, on the other hand, stepped in 'with greater tact and subtlety. They tended to stay longer and seemed much more concerned about getting to the root causes of the conflict.' The women had another advantage: a built-in 'calming effect,' discovered during psychodramas that were part of the guards' training. Enraged men, Sherman found, 'simply could not respond as angrily or violently to the women as to the men." "TIME, May 1, 1972, at 60. 
war on all of the conditions of poverty, discrimination, and alienation must be waged in order to prevent their effects. A similar re-evaluation of priorities and a rechannelling of imagination, effort, and resources is necessary to develop the comprehensive diversion of those cases which will still come to governmental attention where the emphasis for an effective diversion requires problem-solving techniques rather than simply problem-controlling hardware. 